\title{
Current Situation and Reform of Mental Health Education for Higher Vocational College Students'
}

\author{
Shufen Sun ${ }^{1, a}$ \\ ${ }^{1}$ Shanghai City, Shanghai Jianfeng Vocational Technical College, China, 201900 \\ ${ }^{\mathrm{a}}$ email
}

Keywords: Higher Vocational Education, Mental Health, Problems and Analysis, Education Reform

\begin{abstract}
With the development of economic in our country, process of urbanization continuiously pushing and the pace of people life is gradually accelerating. Emotional problems caused by factors such as life, learning, emotion and so on, often puzzled people in the city. According to statistics, students of vocational college in Shanghai, there are about 34\% suffered problems or long-term psychological and need to reform the current situation of mental health education immediately. Based on the results of research in Shanghai. This paper analyzes the current situation of mental health education in Higher Vocational College Students in Shanghai with related working experience and puts forward some practical suggestions for reform.
\end{abstract}

\section{Introduction}

Higher vocational education is the important period for students to enter society and training the senior technical personnel with a large number. The level of higher vocational education has the important significance of individual students, students family and even countries. However in the investigation of Vocational Students' in Shanghai, I found that a considerable proportion of the students have some psychological problems which is concentrated on distraction, passive, irritability, rebellious etc., which caused the our attention. Psychological problems will influence future seriously in the growth of the transition period of Higher Vocational Students. The author carried out a survey according to the psychological problems of higher vocational college students in Shanghai, the content of investigation includes psychological status, satisfaction degree of mental health education and the view of the students to school of students, when the results of the survey focused on analyzing, the author found that, the main reason for the education level of mental health is low, in addition to emotional problems, learning pressure students psychological health problems. We still in the initial stage compared with the developed countries. When the students have problems of mental health, can get help in time, resulting in psychological problems gradually developed into a psychological disease. Therefore, we need to start from the psychological health education, and help them to solve problems of mental health.

\section{Current Situation of Mental Health Education for Higher Vocational College Students in Shanghai}

The author conducted a survey to teaching situation and students' opinions in 19 etc. Vocational Colleges, such as Shanghai Donghai Vocational and Technical College, Shanghai Xinqiao Vocational and Technical College, Shanghai Xingjian Vocational and Technical College, Shanghai Polytechnic Vocational and Technical College of Urban Management. Colleges and universities using the way of investigation of interview, to understand the composition and the spiritual appearance of the school. Colleges and universities using the way of questionnaire, collected twelve data from the students' opinion of school teaching mode and the satisfaction of mental health education. The author makes an overview of the current situation to mental health education of students in higher vocational college of Shanghai after analyzing the results of the survey.

Lack of mental health education in some colleges. In the survey, the author found that $25 \%$ of higher vocational colleges in Shanghai are lack of mental health education. The author found that 
lack of mental health education in schools mainly has the following three points in the investigation of the relevant person in charge of the school. The first is the mental health consciousness of college management is weak. The age of students is 18-20, but for the management, there is no need to carry out mental health education that they think their mental health is mostly mature, which leads to the lack of mental health education in some universities and colleges. The author holds the opposing view for that. First of all, the mental health problems are universal which is the people of any age could have, and there's no essential connection between the generation and the age. Moreover, the students of higher vocational colleges are in the transition period of the society with fluctuations of psychology. They need the education of psychological health to ensure the transition of students smoothly.

Secondly, lack of teaching resources in schools. There are some schools have limited strength in the investigation of Higher Vocational Colleges which led to carry out mental health education with not have sufficient funds and conditions. The emergence of this problem also has its external factors that the education of mental health in the past is not highly valued in our country, the real cause of the extreme events that started in recent years. Therefore, the lack of social training to make the talent is scarce of the people can engage in mental health education which also improves the psychological education personnel employment standards. But for requirements of higher employment are difficult to be met of general school. Thirdly, the acceptance level is low of students'. The author found that there are a considerable proportion of vocational college students on mental health education have resistance in the survey, which have two accepts. On the one hand, the psychological health education has nothing to do with the professional. This course is regarded as "useless class" by some students, which makes the class attendance rate lower. On the other hand, some students think that they do not have mental health problems, even if there is no external help of psychological problems or embarrassed to accept outside help. These two kinds of thinking are one-sided, and have a negative impact on the promotion of mental health education in higher vocational colleges.

The mental health education level is low in most colleges. The effect of mental health education largely depends on the level of mental health education. But the author found that the low level of psychological education is a common problem in higher vocational colleges in the investigation of 19 Higher Vocational Colleges in Shanghai. It's more common phenomenon which mainly reflect to play the phone in the class. Besides, the school is more in class mode to take classes, resulting in the boring atmosphere, poor teaching effect etc in the class. Students reflect the lack of interest in classroom, passion for teaching, curriculum content is easy to forget, etc generally. This shows that has become a great importance problem already and reflect low level of psychological education in school.

The author concludes that there are three reasons for this problem. The first is difficult to organize the course. Part of the colleges and universities take semester and the organization form of small class teaching in the mental health education curriculum organization, this form of curriculum organization aims to quantify the course and to arrange better, however, it is a long-term process of mental health education, can not take a organization of conventional classroom. Although this quantitative model can make each semester has a curriculum arrangement, but the course can not be distributed in the semester. It is difficult to be guaranteed of the teaching effect.

Secondly, it is difficult to formulate the teaching form. The characteristics of psychological problems is particularity and privacy, different people have different psychological problems. In the class of mental health education, teachers can only teach certain psychological problems lead to lack of people which influences the teaching result. At the same time, it's hard to carry out a discussion for some students with considering privacy. Even if you hide the name of students, still have a certain impact on the parties, which makes the depth of the course lower. Thirdly, it's difficult to improve the coordination degree of students' effectively. The author found that some schools have recognized the importance of mental health education in the investigation of the schools, which is organizing the work to improve the quality of teaching actively. However, students with low coordination in the work, even in serious condition, serious lack of classroom. It 
affects the enthusiasm of the teachers to a certain extent making it difficult to improve the quality of teaching.

\section{Suggestions on the reform of mental health education for Higher Vocational Students}

In order to enhance the level of Higher Vocational College Students' in mental health education and create a a good campus atmosphere, enhance student learning, to reform the narrow coverage, low level of psychological health education is needed for healthy growth of the students of the escort, the author according to the Shanghai Local Vocational College; mental health education actual situation, combined with the successful experience of domestic and international mental health excellent colleges, of psychological health education in vocational college students put forward some practical operation of the reform ideas.

Strengthening the Construction of Teaching Staff in Mental Health Education. One of the important reasons for the lack of mental health education of Higher Vocational Colleges in Shanghai is the lack of teaching staff. We need to carry out work from two angles of society and schools to solve the problems thoroughly. On the social level, the relevant education departments should start from their own, fully understand the importance of mental health education and to take practical measures to support the relevant professional psychological health education, enhance graduates can be employed to ease the lack of professional talents in the market situation which provide the environment of choosing the teacher for Higher Vocational College, and encourage counselors to obtain the certificate of national secondary psychological consultant, so that more of the higher vocational colleges have the ability to employ professional teachers. Society imorove the premise for the popularization of mental health education in Higher Vocational Colleges through a series of work. And at the same time, increase the support of the group of mental health teachers in Higher Vocational Colleges to help them achieve rapid development.

From school, we should first reform the system of policy, so that we can not only pay attention to learning and employment of students' , but also pay attention to the healthy growth of students'. The school realized the importance of mental health education through the change of attitude. Besides, the financial input to the psychological health education, increase investment, hire a professional teaching team and improve teaching ability which is to meet the social requirements of hardware and standards of students need in psychological health education, can truly provide students with quality of mental health education. The school should correct the students' understanding of mental health through the right guidance and make students accept the course of psychological health to the establishment of mutual trust between teachers and students, so that students can support the work of teachers, reduce the difficulty of the work of teachers, enhance the speed of development of the teachers team.

Improve the Course Content and Teaching Materials Preparation. In recent years, the multiple vicious incidents of campus has occured that alarm bell of psychological health education and some of the mental health education courses in Shanghai are taken from the former Soviet Union or the European and American countries. Due to the different cultural environment, the content of these courses can not be well adapted to our country. The mental health education of our country began in the ninety's of last century, although it has experienced more than 20 years of development, but the development speed is slow, the level of development is low, can not meet the actual needs. The content of course is the soul of the curriculum, in order to improve the level of mental health education, we need to improve the content of the course. In this regard, the following reforms need to be carried out. First, the content of the era needs to be selected.

In the modern era, students should be encouraged to look into the psychological problems and take a positive attitude to deal with the psychological problems and to help students to open their hearts to solve personal problems with right attitude. Let the students know that it's not terrible of psychological problems which can be completely restored to health as long as through the correct way. Secondly, replace the theory with examples. Teachers used the theory in the teaching in the past, let the students to recognize the meaning of psychological health and to teach students to 
resolve problems of psychological, let it to solve their problems of psychological. But this approach does not operate, so the teaching effect is more poor. In order to improve the teaching effect, teachers should adopt the way of teaching examples instead of the theory, so that students understand the importance of mental health in an example, and enhance the importance of mental health.

Thirdly, guide students to psychological counseling. The purpose of mental health education is to solve the mental health problems of students', but due to the special of psychological health problems, it is difficult to effectively solve the problem through a short period of time. Therefore, the course content should not be limited to "solve the psychological problems", and should be extended to "how to solve the psychological problems", and guide students to the relevant agencies after the emergence of psychological problems timely. In addition to the curriculum reform, it's also very important of the textbook compilation. Textbook is an important carrier of the curriculum, the relevant departments should strengthen the preparation of teaching materials, timely preparation of new textbooks in accordance with the needs of the times, to meet the needs of students. In addition to the curriculum also need activities to organization of mental health publicity and education , such as psychological counseling of college students group , activities of mental health education on May. A large community activities such as wechat platform, E-class, mobile micro classroom network technology support platform for propaganda and education etc., to promote the development of psychological health education from multi angle.

\section{Conclusion}

The author in this paper found that the level of mental health education of Higher Vocational College Students in Shanghai is generally low through the investigation. In the aspect of mental health, the education degree of the students is insufficient, there is a big psychological health risk. The author puts forward the reform suggestions on strengthening the construction of teaching staff and optimizing the course content, and the two aspects of the current situation of mental health education after the analysis of the phenomenon. The higher vocational colleges should also further improve the mental health education system, establishment including education, guidance and assistance to psychological service system, the better helpping for the students to provide mental health in the future.

\section{Reference}

[1] X.Y. Cai. Investigation and countermeasure research on the current situation of mental health education in Higher Vocational Colleges in Yunnan province [D]. Kunming University of Science and Technology, 2012

[2] Y.Chen. Current situation and Countermeasures of mental health education for students in Higher Vocational Colleges in Guangxi [D]. Guangxi Normal University, 2011

[3] G.Y. Su. Based on the study of Higher Vocational Students' mental health education[D]. ,

Xi'an University Of Architecture And Technology, 2014,

[4] J.S. Li. Problems and Countermeasures of mental health education of Higher Vocational College Students [D]. Hainan University, 2015

[5] M.Lei. Construction of psychological health education psychology: connotation, research object and discipline system [J]. Journal of Sichuan University of Science and Engineering (SOCIAL SCIENCE EDITION), 2014, V.29; No.12503:31-42. 